\title{
Prevalence of obstructive sleep apnoea in sleep consultations in Burkina Faso: Implications for monitoring
}

\author{
G Bougma, ${ }^{1} \mathrm{MD}$; G Ouédraogo, ${ }^{1} \mathrm{MD} ;$ G Badoum, ${ }^{1} \mathrm{MD}$; M Ouédraogo, ${ }^{1} \mathrm{MD}$ \\ ${ }^{1}$ Department of Pulmonology, University Hospital Yalgado Ouedraogo, Ouagadougou, Burkina Faso \\ ${ }^{2}$ Department of Pulmonology, University Hospital Souro Sanou, Bobo Dioulasso, Burkina Faso \\ ${ }^{3}$ Department of Pulmonology, Regional Hospital of Ouahigouya, Ouahigouya, Burkina Faso \\ ${ }^{4}$ Department of Pulmonology, National Hospital Lamordé, Niamey, Niger
}

A R Ouédraogo, ${ }^{1} \mathrm{MD}$; A Tiendrebeogo, ${ }^{1} \mathrm{MD} ; \mathrm{K}$ Boncoungou, ${ }^{1} \mathrm{MD} ; \mathrm{E}$ Birba, ${ }^{2} \mathrm{MD} ; \mathrm{G}$ A Ouédraogo,${ }^{3} \mathrm{MD}$; M M Assao Neino, ${ }^{4} \mathrm{MD}$;

Corresponding author: A R Ouedraogo (oarisgou@yahoo.fr)

\begin{abstract}
Background. Obstructive sleep apnoea syndrome (OSAS) is the most common respiratory disorder related to sleep. Its prevalence in developed countries varies from $3 \%$ to $28 \%$. In several African countries, including Burkina Faso, this syndrome is still under-diagnosed and goes largely untreated. It is necessary to conduct studies in different contexts to determine the characteristics and develop the strategies for management of OSAS.

Objectives. To determine the prevalence of OSAS in Burkina Faso.

Methods. This prospective study recruited 106 patients coming for consultation for sleep disorders at the Yalgado Ouedraogo University Hospital Center, who responded to a self-questionnaire and were diagnosed by respiratory polygraphy.

Results. A total of 77 patients (72.6\%) had OSAS. The male to female ratio was 1.4:1 and the mean (standard deviation) age was 47.8 (12.8) years. The majority of the patients (53.8\%) were obese. The main reason for consultation was snoring ( $84 \%)$, followed by hypopnea-apnoea reported (59.4\%) and daytime sleepiness (45.3\%). The most common comorbidity factor was hypertension (50\%), followed by decreased libido (16\%) and diabetes (13.2\%). A continuous positive-pressure (CPAP) machine was prescribed to $51.25 \%$ of the patients, but only $22 \%$ were able to acquire it.

Conclusion. The monitoring of OSAS is relatively new in Burkina Faso. This study showed the profile of patients with OSAS and difficulties in accessing continuous positive airway pressure (CPAP) devices for treatment.
\end{abstract}

Afr J Thoracic Crit Care Med 2020;26(3):74-80. https://doi.org/10.7196/AJTCCM.2020.v26i3.042

Obstructive sleep apnoea syndrome (OSAS) is the most common sleep-related breathing disorder. It is characterised by a cessation or a decrease of respiratory air flow. ${ }^{[1]}$ OSAS affects nearly $5 \%$ of the global adult population and is responsible for numerous cardiovascular complications such as hypertension, coronary artery disease, stroke and heart failure. ${ }^{[2]}$ The disease is marked by a deterioration in quality of life. ${ }^{[2,3]}$ Therefore, OSAS represents a significant public health problem.

Sixty percent of OSAS patients remain undiagnosed globally. ${ }^{[4]}$ The risk factors for OSAS are multiple and include being overweight, age, male gender, certain endocrine pathologies and morphological predispositions to upper airway obstruction. ${ }^{[5]}$ In several African countries, including Burkina Faso, OSAS is still under-diagnosed owing to the expensive equipment required to record sleep disordered breathing. The diagnosis of OSAS is based on a night recording of breathing using either polysomnography or respiration polygraphy. Accessibility to treatment is also a major challenge. Because of the cardiovascular complications and the large population that goes undiagnosed, it is important to investigate the prevalence of this condition in Burkina Faso.

\section{Methods}

Framework and study population

This study took place in Ouagadougou, the capital city of Burkina Faso. The population of Burkina Faso was estimated at 19034397 inhabitants in 2016, with 2637303 inhabitants living in Ouagadougou. ${ }^{[7]}$ It is a landlocked country located in West Africa.

The study was carried out in the Pulmonology Department of Ouagadougou University Hospital Yalgado Ouedraogo (CHU-YO), which has the only public unit for the management of sleep-related respiratory diseases in Burkina Faso. The consultations were conducted twice a week by two pulmonologists trained in the management of sleep-related breathing disorders. The unit had only one CIDELEC 102L respiratory polygraph machine (CIDELEC, France). The cost of testing was USD54.07. Patients who were unable to pay these fees were exempted.

Burkina Faso does not have a supplier for the marketing and maintenance of continuous positive airway pressure (CPAP) devices. CPAP devices are ordered from abroad by patients. Titrations and followups are provided by the unit's doctors. In the private sector, only one medical clinic was able to diagnose OSAS using respiratory polygraphy. 


\section{Population and type of study}

This was a prospective study conducted from 1 April 2016 to 31 March 2017 in the Pulmonology Department of CHU-YO. It involved patients with functional OSAS symptoms who were referred by other practitioners or who presented on their own for sleep consultation.

\section{Data collection}

An anonymous survey record collected sociodemographic characteristics, past medical histories, clinical data, polygraphic and therapeutic data. The Epworth scale was used to evaluate daytime sleepiness and the Pichôt scale for fatigue. A CIDELEC CID 102L respiratory polygraph (level III (Cidelec, France)) was used for the recordings. The polygraph included a continuous oximetry sensor, tracheal sound sensor, suprasternal pressure sensor, nasal flow sensor (nasal canula), and sensors for thoracic and abdominal movements. The questionnaire was administered during the consultation as an interview and explained in the local language for patients who did not speak French. Details of the history of the disease, the past medical history, and a physical examination with measurement of the anthropometric parameters (weight, height, neck and abdominal circumference) were recorded. The patients were then referred for an ear, nose and throat (ENT) consultation for a possible local cause. On the night of the polygraphic recording, an intern ( 7 th year of medicine) measured the pulse and the blood pressure. The reading of the results was carried out by a pulmonologist trained on sleep-related breathing pathologies.

OSAS is defined by the presence of criteria A or B and C:

A. Excessive daytime sleepiness not explained by other factors;

B. At least two of the following criteria not explained by other factors: severe daily snoring, sensations of choking or suffocation during sleep, unrepairing sleep, daytime fatigue, difficulty concentrating, nocturia (more than one urination per night);

C. Polysomnographic or polygraphic criteria: apnoeas + hypopnoeas $\geq 5$ per hour of sleep (Apnoea-Hypopnoea Index (AHI) $\geq 5$ ). ${ }^{[11,13]}$

We define a casual snorer as a person who snores less than three nights a week and a usual snorer as a person who snores more than three nights a week. ${ }^{[12]}$ Other operational definitions are summarised in Table 1.
Depending on the severity, clinical impact and results of the investigations, the appropriate treatment was proposed according to the 2010 French recommendations for clinical practice. ${ }^{[13]}$

CPAP was recommended as initial therapy for patients with severe OSAS even in the absence of symptoms and moderate OSAS with excessive daytime sleepiness and/or cardiovascular or respiratory comorbidities.

A mandibular advancement device (MAD) was recommended for patients with mild to moderate OSAS in the absence of symptoms and comorbidities, or for patients who declined or failed to adhere to positive airway pressure therapy or who had a preference for this treatment.

Weight loss and exercise were recommended to all patients with OSAS who were overweight or obese. Positional treatment, which consisted of avoiding the supine position during sleep, has been recommended for mild to moderate positional OSAS in the absence of significant obesity.

\section{Statistical analysis}

The data were analysed using the Epi Info 7.2 statistics software (Centres for Disease Control and Prevention, USA). Pearson's Gross $\chi^{2}$ test or Fischer's exact test were used to compare categorical variables. Mean values were presented with the standard deviation as the dispersion index. Pearson's linear correlation coefficient $(r)$ was used to measure correlation between quantitative variables. Associations between variables were considered statistically significant at the probability threshold of $p<0.05$.

\section{Ethical considerations}

The study was carried out with respect for the anonymity and confidentiality of the information collected. It was carried out in accordance with bioethical laws and with good clinical practice. We obtained informed consent from all participants before enrolment.

\section{Results}

\section{Sociodemographic and clinical data}

During the study period, 1784 patients were seen in the Pulmonology Department of CHU-YO. Among these, 5.9\% $(n=106)$ came for sleep consultation. The sociodemographic and clinical data for all the patients are summarised in Table 2.

\section{Table 1. Operational definitions}

\begin{tabular}{|c|c|c|c|c|}
\hline EDSS $^{[8]}$ & Pichôt Fatigue Scale ${ }^{[9]}$ & $\mathrm{AC}$ and $\mathrm{NC}{ }^{[10]}$ & $\begin{array}{l}\text { Level of severity of the OSAS } \\
\text { as defined by the AHI }\end{array}$ & $\begin{array}{l}\text { Quantification of snoring as } \\
\text { classified in }{ }^{[12]}\end{array}$ \\
\hline \multirow{2}{*}{$\begin{array}{l}\text { Score <11: normal } \\
\text { vigilance }\end{array}$} & - Score $\leq 22$ : normal & Normal if: & \multirow{2}{*}{$\begin{array}{l}\text { Mild: between } 5 \text { and } 15 \\
\text { events per hour }\end{array}$} & \multirow{2}{*}{$\begin{array}{l}\text { Non-snorer: person whose SI is } \\
<30 / \mathrm{h}\end{array}$} \\
\hline & $\begin{array}{l}\text { - Score }<22 \text { : excessive } \\
\text { fatigue }\end{array}$ & $\begin{array}{l}\text { Men: } A C<94 \mathrm{~cm} \\
\text { and } \mathrm{NC}<43 \mathrm{~cm}\end{array}$ & & \\
\hline $\begin{array}{l}\text { Score between } 11 \text { and } \\
\text { 15: sleep deficit }\end{array}$ & & $\begin{array}{l}\text { Women: } \mathrm{AC}<80 \\
\mathrm{~cm} \text { and } \mathrm{NC}<41 \mathrm{~cm}\end{array}$ & $\begin{array}{l}\text { Moderate: between } 15 \text { and } 30 \\
\text { events per hour }\end{array}$ & $\begin{array}{l}\text { Moderate snorer: SI between } 30 \\
\text { and 100/h }\end{array}$ \\
\hline \multirow[t]{2}{*}{$\begin{array}{l}\text { Score } \geq 16 \text { : signs of } \\
\text { excessive daytime } \\
\text { sleepiness }\end{array}$} & & & $\begin{array}{l}\text { Severe: } 30 \text { and more events } \\
\text { per hour }\end{array}$ & $\begin{array}{l}\text { Average snorer: SI between } 100 \\
\text { and } 300 / \mathrm{h}\end{array}$ \\
\hline & & & & Severe snorer: $\mathrm{SI}>300 / \mathrm{h}$ \\
\hline
\end{tabular}


The male to female ratio was 1.4:1. The average (SD) age of patients was 47.8 (12.8) years with extremes of 18 and 79 years. There were $78.3 \%(n=83)$ patients who were employed. The percentage of married and college-educated patients was $78.3 \%(n=83)$ and $51.9 \%(n=55)$, respectively. Snoring was the main reason for consultation and was

\begin{tabular}{|c|c|}
\hline Variables & Frequency, $n(\%)$ \\
\hline \multicolumn{2}{|l|}{ Gender } \\
\hline Male & $62(58.5)$ \\
\hline Female & $44(41.5)$ \\
\hline \multicolumn{2}{|l|}{ Age (years) } \\
\hline$<30$ & $8(7.5)$ \\
\hline $30-39$ & $21(20)$ \\
\hline $40-49$ & $35(33)$ \\
\hline $50-59$ & $25(23.5)$ \\
\hline$\geq 60$ & $17(16)$ \\
\hline \multicolumn{2}{|l|}{ Marital status } \\
\hline Married & $83(78.3)$ \\
\hline Other & $23(21.7)$ \\
\hline \multicolumn{2}{|l|}{ Professional status } \\
\hline Active & $83(78.3)$ \\
\hline Inactive & $23(21.7)$ \\
\hline \multicolumn{2}{|l|}{ BMI $\left(\mathrm{kg} / \mathrm{m}^{2}\right)$} \\
\hline $18.5-25$ & $15(14.2)$ \\
\hline $25-30$ & $33(31.1)$ \\
\hline$>30$ & $58(54.7)$ \\
\hline \multicolumn{2}{|l|}{ NC } \\
\hline Normal & $66(62.3)$ \\
\hline Excessive & $40(37.7)$ \\
\hline \multicolumn{2}{|l|}{$\mathrm{AC}$} \\
\hline Normal & $31(29.2)$ \\
\hline Excessive & $75(70.8)$ \\
\hline \multicolumn{2}{|l|}{ Past medical history/comorbidities } \\
\hline Smoking & $20(18.9)$ \\
\hline Alcohol consumption & $39(36.8)$ \\
\hline HTN & $53(50)$ \\
\hline Decreased libido/erectile dysfunction & $20(18.9)$ \\
\hline Asthma & $18(17.0)$ \\
\hline Depression & $18(17.0)$ \\
\hline Diabetes & $14(13.2)$ \\
\hline Cardiopathies & $8(7.5)$ \\
\hline COPD & $1(0.9)$ \\
\hline HIV & $1(0.9)$ \\
\hline \multicolumn{2}{|l|}{ Chief complaint } \\
\hline Snoring & $89(84.0)$ \\
\hline $\begin{array}{l}\text { Feeling of choking/suffocation } \\
\text { during sleep }\end{array}$ & $63(59.4)$ \\
\hline Morning fatigue & $59(55.7)$ \\
\hline Nocturia & $56(52.8)$ \\
\hline Daytime sleepiness & $48(45.3)$ \\
\hline Morning headaches & $35(33.01)$ \\
\hline Respiratory pauses & $23(21.7)$ \\
\hline
\end{tabular}

reported by $84 \%$ ( $n=89$ ) of the patients, followed by the feeling of choking during sleep in $59.4 \%(n=63)$ of patients. Hypertension was the main comorbidity in $50 \%(n=53)$ of the patients. More than a third of the patients $36.8 \%$ ( $n=39$ ) consumed alcohol, while $18.9 \%$ $(n=20)$ were smokers. Obese patients accounted for $53.8 \%(n=57)$ of the study population. The mean (SD) body mass index (BMI) was $31.7 \mathrm{~kg} / \mathrm{m}^{2}$ (6.9) with extremes of 19 and $50 \mathrm{~kg} / \mathrm{m}^{2}$. Neck and abdominal circumferences were excessive in $37.7 \%(n=40)$ and $70.8 \%(n=75)$ of the patients, respectively. More than a third of the patients $(36.8 \%$; $n=39$ ) felt that the duration of their sleep was not enough. Excessive fatigue was found in $41.5 \%(n=44)$ of patients using the Pichôt scale. A quarter of the patients $(25.5 \% ; n=27)$ had a sleep deficit and $21.7 \%$ ( $n=23$ ) had scores of excessive daytime sleepiness as determined using the Epworth scale. There was a strong positive correlation between fatigue and drowsiness $(r=0.64 ; p<0.001)$. The ENT examination identified cases of sinusitis $(9.4 \% ; n=10)$, macroglossia $(6.6 \% ; n=7)$ and nasolabial polyposis $(2.8 \% ; n=3)$.

\section{Respiratory polygraphy and treatment}

Respiratory polygraphy was performed in all patients and the results are summarised in Table 3 . The average (SD) duration of the recording

Table 3. Respiratory polygraphy data $(N=106)^{*}$

\begin{tabular}{|c|c|}
\hline & Frequency, $n(\%)$ \\
\hline \multicolumn{2}{|l|}{$\mathrm{AHI}(/ \mathrm{h})$} \\
\hline$<5$ & $26(24.5)$ \\
\hline $5-15$ & $30(28.3)$ \\
\hline $15-30$ & $20(18.9)$ \\
\hline$>30$ & $30(28.3)$ \\
\hline \multicolumn{2}{|l|}{ Mean nocturnal $\mathrm{SpO}_{2}(\%)$} \\
\hline$<95 \%$ & $67(63.2)$ \\
\hline$\geq 95 \%$ & $39(36.8)$ \\
\hline \multicolumn{2}{|l|}{$\mathrm{SpO}_{2}$ on waking up (\%) } \\
\hline$<95 \%$ & $26(24.5)$ \\
\hline$\geq 95 \%$ & $80(75.5)$ \\
\hline \multicolumn{2}{|l|}{ ODI } \\
\hline$<10$ & $29(27.3)$ \\
\hline $10-20$ & $25(23.6)$ \\
\hline$\geq 20$ & $52(49.1)$ \\
\hline \multicolumn{2}{|l|}{ SI } \\
\hline Non-snorer & $34(32.1)$ \\
\hline Moderate snorer & $18(17)$ \\
\hline Average snorer & $22(20.7)$ \\
\hline Severe snorer & $32(30.2)$ \\
\hline \multicolumn{2}{|c|}{ Type of sleep apnoea syndrome $(n=80)$} \\
\hline Obstructive & $77 / 80(96.3)$ \\
\hline Central & $3 / 80(3.7)$ \\
\hline \multicolumn{2}{|c|}{$\begin{array}{l}\text { Predominant position of apnoea occurrence } \\
(n=80)\end{array}$} \\
\hline Supine position & $79(98.7)$ \\
\hline Left lateral decubitus & $47(58.7)$ \\
\hline Right lateral decubitus & $41(51.2)$ \\
\hline Ventral decubitus & $18(22.5)$ \\
\hline
\end{tabular}


was 7 (0.7) hours. OSAS was confirmed in $72.6 \%(n=77)$ of the patients and was classified as severe in $28.3 \%(n=30)$ of the patients. The predominant position of apnoea occurrence was dorsal decubitus (98.7\%). Mean (SD) $\mathrm{SpO}_{2}$ at wakefulness was $96 \%$ (2.2), with extremes of $83 \%$ and $98 \%$; at night it was $94.1 \%$ (3.6), with extremes of $76 \%$ and $98 \%$. There was a strong positive correlation between AHI and nocturnal $\mathrm{SpO}_{2}(r=0.63 ; p<0.001)$. The oxygen desaturation index (ODI) was $\geq 20$ episodes per hour in $49.1 \%(n=52)$ patients. The snoring index (SI) revealed that $30.2 \%(n=32)$ of the patients were severe snorers. The factors associated with OSAS are summarised in Table 4. There was a positive correlation between AHI and neck circumference $(\mathrm{NC})(r=0.45 ; p<0.001)$ and abdominal circumference (AC) $(r=0.48 ; p<0.001)$. There was also a correlation between AHI and BMI (Fig. 1), Pichôt fatigue scale (Fig. 2) and Epworth daytime sleepiness scale (Fig. 3).

All patients with OSAS were advised to change their lifestyle and diet. Postural treatment (tennis ball in a vest to stop the patient lying on their back) was offered to $11.7 \%(n=9 / 77)$ of the patients. A MAD device was indicated in $35 \%(n=27 / 77)$ of the patients; however, no patient was able to purchase the machine. CPAP treatment was prescribed to $53.2 \%(n=41 / 77)$ of the patients. However, only $21.9 \%$ $(n=9 / 41)$ of these patients were able to acquire the CPAP device. The lack of financial means for the acquisition of the device was mentioned by $78.1 \%(n=32 / 41)$ of the patients. A total of $88.7 \%(n=68)$ of patients with OSAS were lost to follow-up.

\section{Discussion}

Our study concerned patients referred for a sleep consultation with functional symptoms suggestive of OSAS. The monitoring of OSAS is relatively new in Burkina Faso. This was the first study in the country to describe the incidence of OSAS. We found that the prevalence of OSAS was $72.6 \%$ in our study. Studies in Vietnam ${ }^{[14]}$ and Morocco ${ }^{[15]}$ reported a prevalence of $87.1 \%$ and $56.7 \%$, respectively.

In our study, the majority of patients were men (58.5\%), who were 2.6 times more likely to have OSAS than women (odds ratio (OR) 2.6; $95 \%$ confidence interval (CI) $1.1-6.3 ; p=0.04$ ). The literature states that the prevalence of OSAS is higher in men than in women (sex ratio of 3:1) due to morphological differences and hormonal factors, especially in the first five decades. ${ }^{[16,17]}$

Beyond the age of 50, the prevalence of OSAS in women increases, suggesting that menopause may be a risk factor for OSAS and hormone replacement therapy may be protective. ${ }^{[16,17]}$ The average (SD) age of our patients was 47.8 (12.8) years with extremes of 18 and 79 years. The prevalence of OSAS increased almost linearly in adults up to age 65 , independently of other risk

\begin{tabular}{|c|c|c|c|}
\hline Variable & OSAS, $n(\%)$ & OR $(95 \% \mathrm{CI})$ & $p$-value \\
\hline \multicolumn{4}{|l|}{ Gender } \\
\hline Female & $27(61.4)$ & \multirow{2}{*}{$2.6(1.1-6.3)$} & 0.04 \\
\hline Male & $50(80.6)$ & & \\
\hline \multicolumn{4}{|l|}{ Age (years) } \\
\hline$<48$ & $39(69.6)$ & \multirow{2}{*}{$0.7(0.3-1.7)$} & 0.4 \\
\hline$\geq 48$ & $38(76)$ & & \\
\hline \multicolumn{4}{|l|}{$\mathrm{NC}$} \\
\hline Normal & $46(69.7)$ & \multirow{2}{*}{$1.5(0.6-3.7)$} & 0.38 \\
\hline Excessive & $31(77.5)$ & & \\
\hline \multicolumn{4}{|l|}{$\mathrm{AC}$} \\
\hline Normal & $18(58.1)$ & \multirow{2}{*}{$2.6(1.1-6.5)$} & 0.03 \\
\hline Excessive & $59(78.7)$ & & \\
\hline \multicolumn{4}{|c|}{ History of hypertension } \\
\hline Yes & $41(77.4)$ & \multirow{2}{*}{$0.6(0.3-1.5)$} & 0.27 \\
\hline No & $36(67.9)$ & & \\
\hline \multicolumn{4}{|l|}{ Smoking } \\
\hline Yes & $17(85)$ & \multirow{2}{*}{$0.4(0.1-1.5)$} & 0.16 \\
\hline No & $60(69.8)$ & & \\
\hline \multicolumn{4}{|c|}{ Alcohol consumption } \\
\hline Yes & $31(79.5)$ & \multirow{2}{*}{$0.5(0.2-1.4)$} & 0.23 \\
\hline No & $46(68.7)$ & & \\
\hline \multicolumn{4}{|c|}{ Sufficient sleep } \\
\hline Yes & $49(73.1)$ & \multirow{2}{*}{$0.9(0.3-2.2)$} & 0.88 \\
\hline No & $28(71.8)$ & & \\
\hline \multicolumn{4}{|l|}{ Pichôt scale } \\
\hline$\leq 22$ & $37(59.7)$ & \multirow{2}{*}{$6.7(2.1-21.2)$} & $<0.001$ \\
\hline$>22$ & $40(90.9)$ & & \\
\hline
\end{tabular}




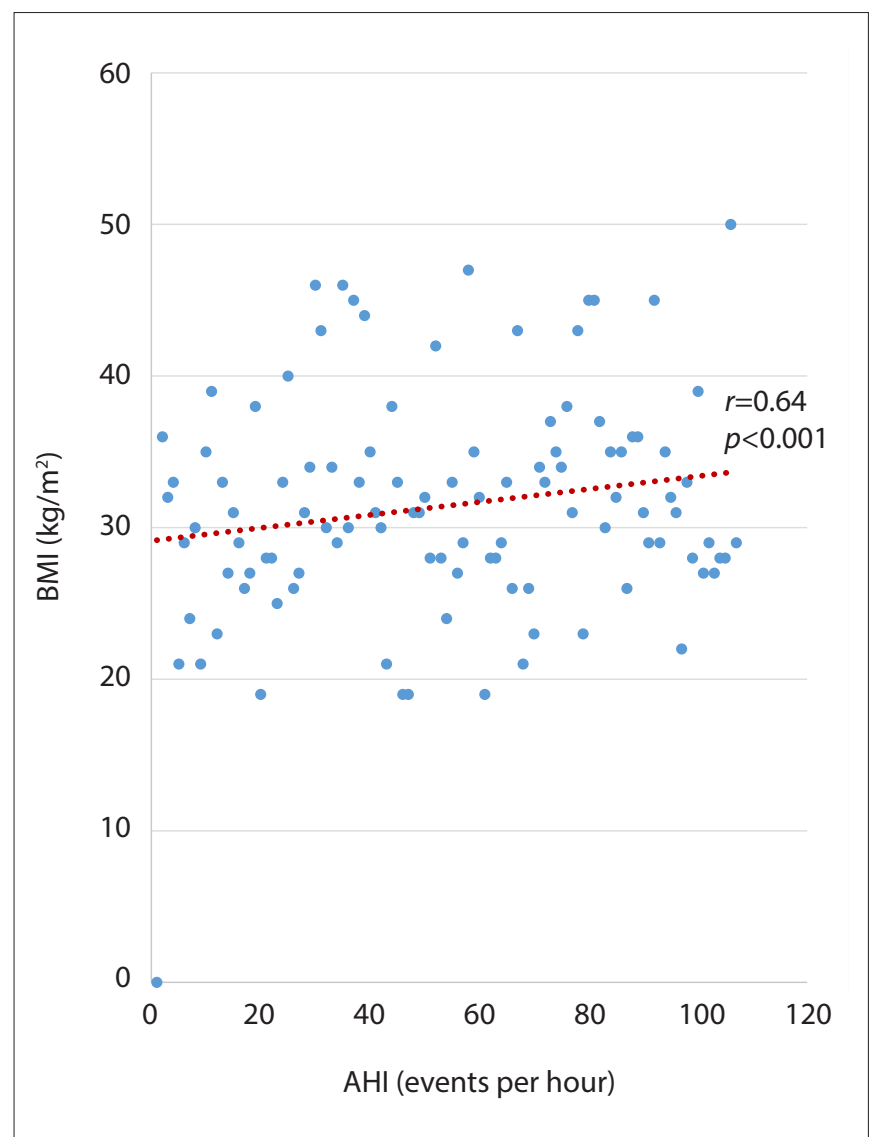

Fig. 1. Correlation between AHI and BMI. (AHI = apnoea-hypopnoea index; $B M I=$ body mass index.)

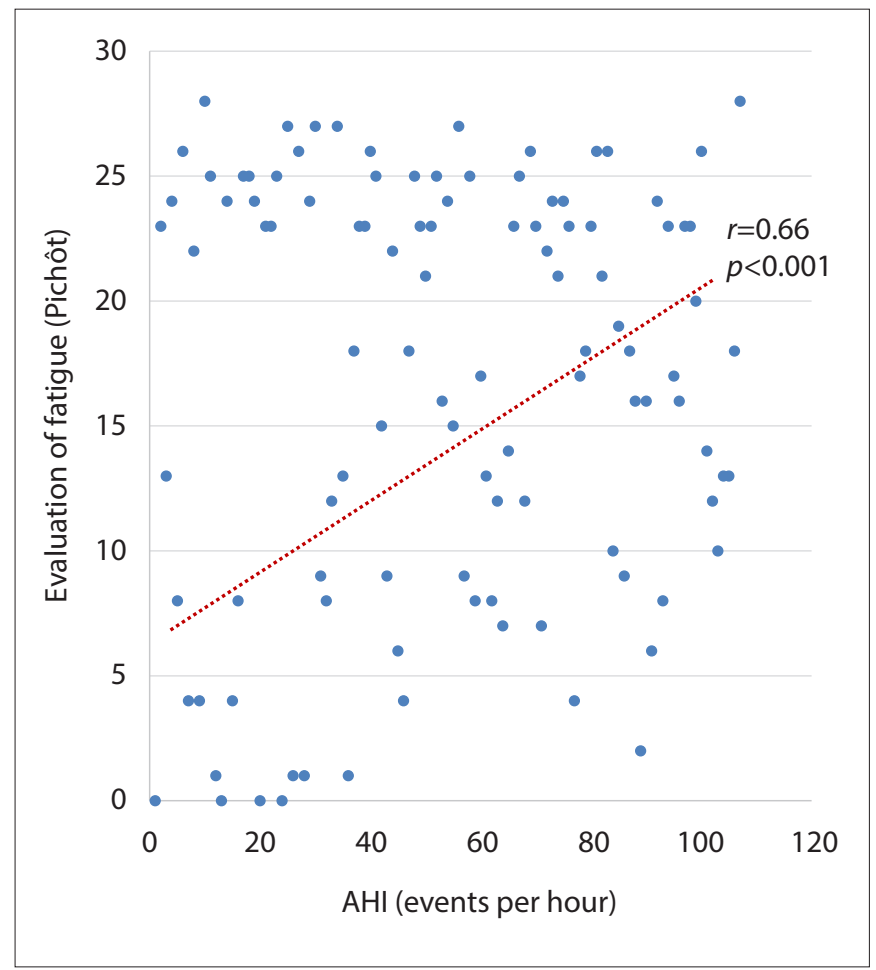

Fig. 2. Correlation between AHI and fatigue assessment on the Pichôt scale. $($ AHI = apnoea-hypopnoea index.)

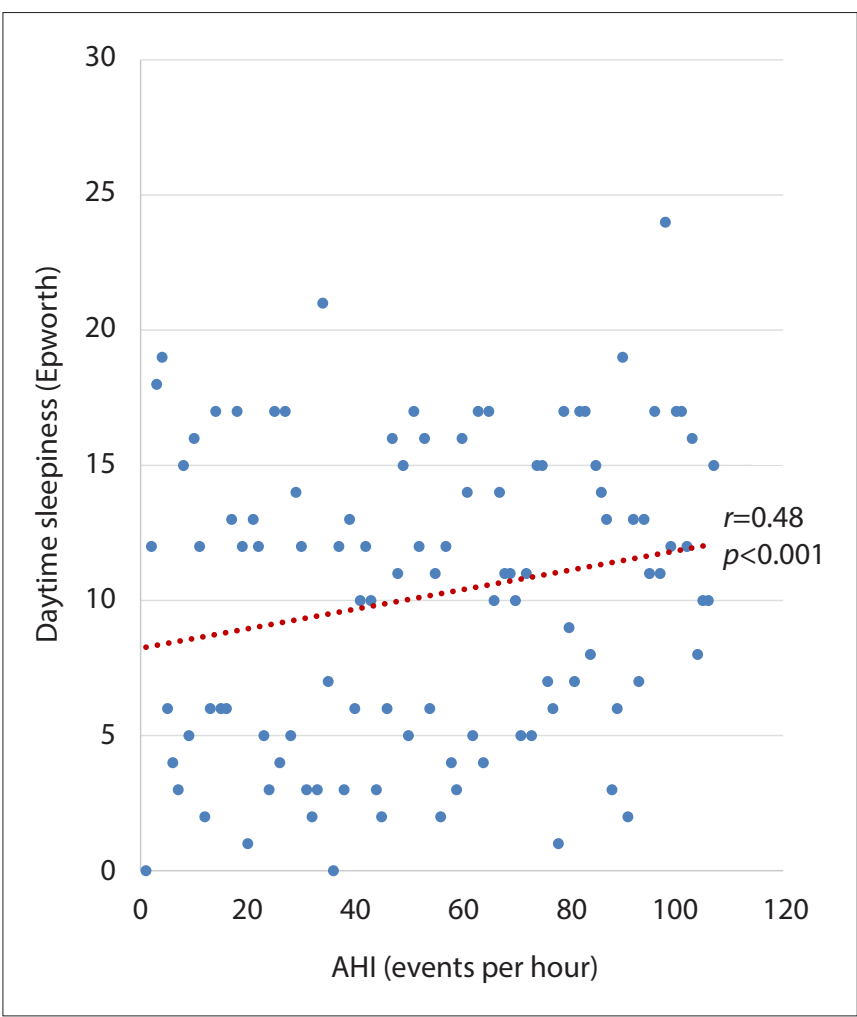

Fig. 3. Correlation between AHI and daytime sleepiness on the Epworth scale. $($ AHI = apnoea-hypopnoea index. $)$

factors. ${ }^{[18]}$ More than half (54.7\%) of the patients were obese. There was a correlation between the AHI and $\mathrm{NC}(r=0.45 ; p<0.001)$ and $\mathrm{AC}(r=0.48 ; p<0.001)$.

Excessive AC was associated with onset of OSAS (OR 2.6; 95\% CI $1.1-6.5 ; p=0.03)$. Obesity is classically known to be a risk factor for OSAS because it can cause narrowing of the airways due to excess fatty tissue around the neck. Several epidemiological studies have confirmed an increase in the prevalence of OSAS in overweight individuals. ${ }^{[5,18]}$

Snoring, often noted by a spouse, was the most common reason for consultation (84\%) in the present study. Sixty percent of men and $40 \%$ of middle-aged women (40 - 60 years) are habitual snorers. ${ }^{[19]}$ Snoring is almost constant in OSAS. ${ }^{[19,20]}$ However, snoring is not synonymous with OSAS.

More than half of our patients (54.3\%) presented with excessive fatigue and $21.7 \%$ with excessive daytime sleepiness. These signs are thought to be responsible for a concentration disorder, memory problems and a decline in intellectual performance. ${ }^{[18,21]}$ This could have repercussions on the professional performance of the $78.3 \%$ of patients in our study who were employed. The feeling of choking felt by the patients (59.4\%) and/or the occurrence of respiratory pauses (21.7\%) was due to obstruction of the upper airways.

Half of our patients had hypertension. OSAS is a major cause of hypertension. ${ }^{[22]}$ A proportion of $30 \%$ to $40 \%$ of patients with hypertension would have OSAS and $50 \%$ of patients with OSAS would be hypertensive. ${ }^{[22]}$ The results of many clinical studies strongly suggest that OSAS is an independent risk factor for cardiovascular diseases such as hypertension, coronary artery disease, stroke and 
heart failure. ${ }^{[22]}$ Several mechanisms have been suggested to link OSAS and vascular diseases, including increases in sympathetic activation, oxidative stress, inflammation, endothelial dysfunction, coagulation and metabolic dysregulation. ${ }^{[22]}$

Asthma was present in $17 \%$ of our patients. Asthmatics have an increased risk of sleep apnoea and apnoea can worsen asthma by increasing inflammation. ${ }^{[23]}$ Recent data suggested that OSAS is an independent risk factor for asthma exacerbations. ${ }^{[23]}$ Neuromechanical reflex bronchoconstriction, gastroesophageal reflux, inflammation (local and systemic), and the indirect effect on dyspnoea of OSASinduced cardiac dysfunction have been suggested as mechanisms that lead to worsening asthma in patients with concomitant OSAS. In patients whose asthma is not controlled by drug therapy, the presence of OSAS should be investigated and properly managed. ${ }^{[23,24]}$

Diabetes was found in $13.2 \%$ of our patients. OSAS is a risk factor for diabetes. A study by Shaw ${ }^{[25]}$ found that $40 \%$ of people with OSAS have diabetes and that the prevalence of OSAS can reach $23 \%$ in people with diabetes.

The diagnosis of OSAS was established using respiratory polygraphy (level 3 portable respiratory polygraphy with at least 4 signals) in $72.6 \%$ of our patients. Polysomnography in a sleep laboratory is the reference examination for the diagnosis of OSAS. ${ }^{[13]}$ However, it is expensive and not available in Burkina Faso. The diagnostic performance of ventilatory polygraphy was compared with polysomnography. The results of these studies showed that ventilatory polygraphy in a patient with a presumptive clinical diagnosis confirms the diagnosis of OSAS with good specificity. ${ }^{[13]}$ Level 3 portable devices showed good diagnostic performance compared with level 1 sleep tests in adult patients with a high pre-test probability of moderate to severe OSAS and no unstable comorbidities. For patients suspected of having other types of sleep-disordered breathing or sleep disorders not related to breathing, level 1 testing remains the reference standard. ${ }^{[26]}$

Depending on the severity and clinical impact, adequate treatment has been proposed to our patients on the basis of the French 2010 recommendations for clinical practice. ${ }^{[13]}$ All patients with OSAS associated with obesity or who were overweight have benefited from lifestyle and dietary measures to reduce their weight. These measures included nutritional counselling as part of a comprehensive nutritional management. The placement of a MAD device was indicated in $35 \%$ of the patients, but all patients reported they could not obtain the MAD due to its unavailability and the very limited number of trained stomatologists/dentists. CPAP treatment of OSAS was prescribed to $53.2 \%$ of the patients, but only $21.9 \%$ of these patients were able to acquire the CPAP device. Since the first demonstration of the effectiveness of ventilation in the treatment of OSAS in1981, numerous studies have been published confirming its effectiveness on the regression of nocturnal respiratory disorders and the clinical symptoms associated with this pathology ${ }^{[13]}$ Burkina Faso does not have a service provider for the marketing and maintenance of CPAP devices. CPAP devices are ordered from abroad by patients; however, many patients cannot afford the devices. This situation makes it difficult to care for patients with OSAS in a country with competing health priorities. Moreover, it is difficult to retain patients in the healthcare chain, as demonstrated by a loss of $88.7 \%$ of our patients during follow-ups.

\section{Conclusion}

The monitoring of OSAS is relatively new in Burkina Faso. The present study showed some of the characteristics of patients with OSAS. Importantly, we showed that OSAS had a prevalence of $72.6 \%$, in patients with sleep disorders. The majority of patients suffering from OSAS could not access therapeutic devices due to their high costs. Therefore, there is an urgent need to set up a multidisciplinary working group to train practitioners and to develop adequate means for better monitoring of this disease.

\section{Declaration. None.}

Acknowledgements. The authors would like to thank the Espace Francophone de Pneumologie, the French-speaking African Society of Pulmonology, the Burkinabe Society of Pulmonology and the University of SFAX in Tunisia for their help in practical training. Our gratitude also goes to the PATS MECOR programme that provided the training in research methods that contributed to the successful completion of this study.

Author contributions. ARO, GB and MO conceived and designed the study, performed statistical analysis, coordinated the study, drafted and revised the manuscript. EB, GAO, MMA, GB and GO participated in the study design, performed statistical analysis, and revised the manuscript. AT and KB participated in the study design, coordinated the study, drafted and revised the manuscript. All authors read and approved the final manuscript.

Funding. None.

Conflicts of interest. None.

1. Guilleminault C, Tilkian A, Dement WC. The sleep apnoea syndromes. Annu Rev Med 1976;27:465-484. https://doi.org/10.1146/annurev.me.27.020176.002341.

2. Shahar E, Whitney CW, Redline S, et al. Sleep-disordered breathing and cardiovascular disease. Cross-sectional results of the sleep heart health study. Am J Respir Crit Care Med 2001;163(1):19-25. https://doi.org/10.1164/ajrccm.163.1.2001008

3. Findley LJ, Unverzagt ME, Suratt PM. Automobile accidents involving patients with obstructive sleep apnoea. Am Rev Respir Dis 1988;138:337-340. https://doi. org/10.1164/ajrccm/138.2.337

4. Sullivan CE, Issa FG, Berthon-Jones M, Eves L. Reversal of obstructive sleep apnoea by continuous positive airway pressure applied through the nares. Lancet 1981;1:862865. https://doi.org/10.1016/s0140-6736(81)92140-1

5. Young T, Peppard P, Gottlieb D. Epidemiology of obstructive sleep apnoea: A population health perspective. Am J Respir Crit Care Med 2002;165:1217-1239. https://doi.org/10.1164/rccm.2109080

6. Meslier N, Vol S, Balkau B, et al. Prévalence des symptômes du syndrome d’apnées du sommeil. Étude dans une population française d'âge moyen. Rev Mal Respir 2007;24:305-313. https://doi.org/10.1016/S0761-8425(07)91062-1

7. Institut National de la Statistique et de la Démographie (INSD). Annuaire statistique 2016. Burkina Faso. Ouagadougou: INSD, 2017.

8. Johns MW. A new method for measuring daytime sleepiness: The Epworth Sleepiness Scale. Sleep 1991;14:540-545. https://doi.org/10.1093/sleep/14.6.540

9. Gardenas J. Echelles et outils d'évaluation en médecine générale. Le GénéralisteSupplément 2002;2187:54.

10. Liistro G, Kessler R, Rodenstein DO. Aspects cliniques du syndrome d'apnées obstructives du sommeil in: Weitzenblum E, Racineux J-L. Syndrome D’apnées Obstructives du Sommeil. Paris: Masson, 2004:71-80.

11. The report of an American Academy of Sleep Medicine Task Force. Sleep-related breathing disorders in adults: Recommendations for syndrome definition and measurement techniques in clinical research. Sleep 1999;22:667-689.

12. Meslier N. Le ronflement et le ronfleur. Quelle définition? Rev Mal Respir 2006;23:7S40-7S43. https://doi.org/10.1016/S0761-8425(06)72479-2

13. Gagnadoux F, Meurice JC. Recommandations pour la pratique clinique du syndrome d’apnées hypopnées obstructives du sommeil de l'adulte. Rev Mal Respir 2010;27:8068-8133. 
14. Le Thuong V, Dang Vu T, et al. Le syndrome d'apnée obstructive du sommeil au Vietnam. J Fran Viet Pneu 2010;01(02):115.

15. Asmaa J, Mustapha EF, Mohamed T. Sleep apnoea syndrome: Experience of the pulmonology department in Ibn Sina Hospital, Rabat, Morocco. Pan Afr Med J 2012;13:28.

16. Bixler EO, Vgontzas AN, Ten Have T, Tyson K, Kales A. Effects of age on sleep apnea in men: I. Prevalence and severity. Am J Respir Crit Care Med 1998;157(1):144-148. https://doi.org/10.1164/ajrccm.157.1.9706079

17. Bixler EO, Vgontzas AN, Lin HM, et al. Prevalence of sleep disordered breathing in women: Effects of gender. Am J Respir Crit Care Med 2001;163:608-613. https://doi. org/10.1164/ajrccm.163.3.9911064

18. Durán J, Esnaola S, Rubio R, Iztueta A. Obstructive sleep apnoea-hypopnoea and related clinical features in a population-based sample of subjects aged 30 to 70 years. Am J Respir Crit Care Med 2001;163:685-689. https://doi.org/10.1164/ ajrccm.163.3.2005065

19. Lugaresi E, Cirignotta F, Coccagna G, Piana C. Some epidemiologic data on snoring and cardiocirculatory disturbances. Sleep 1980;3:221-224. https://doi.org/10.1093/ sleep/3.3-4.221

20. Sogebi OA, Oyewole EA, Olusoga-Peters OO. Sleep disordered breathing (SDB) experiences associated with snoring in adult Nigerians. Afr Health Sci 2011;11(3):309-314
21. Baldwin CM, Griffith KA, Nieto FJ, O'Connor GT, Walsleben JA, Redline S. The association of sleep-disordered breathing and sleep symptoms with quality of life in the Sleep Heart Health Study. Sleep 2001;24(1):96-105. https://doi.org/10.1093/ sleep/24.1.96

22. Lévy P, Pépin JL, Baguet JP. Le syndrome d’apnées obstructives du sommeil, une cause majeure et encore méconnue d'hypertension artérielle. Méd Sommeil 2006;3(8):19-24 https://doi.org/10.1016/S1769-4493(06)70064-4

23. Lyoussfi H, El Khattabi W, El Bied B, et al. Asthme et syndrome d'apnée obstructive du sommeil (SAOS): Y’a-t-il un rapport? Revue Française d'Allergologie 2014;54:265-275.

24. Alkhalil M, Schulman E, Getsy J. Obstructive sleep apnoea syndrome and asthma: What are the links? J Clin Sleep Medicine 2009;5(1):71-78.

25. Shaw J. Lapnée obstructive du sommeil et le diabète de type 2. Le consensus de la FID Diabetes Voice 2008;53(3):29-32.

26. El Shayeb M, Topfer LA, Stafinski T, Pawluk L, Menon D. Diagnostic accuracy of level 3 portable sleep tests versus level 1 polysomnography for sleep-disordered breathing: A systematic review and meta-analysis. CMAJ 2014;186(1):E25-51. https://doi. org/10.1503/cmaj.130952

Accepted 29 July 2020 